\title{
ANNOTATION \\ Eye Conditions among Pupils in Schools for the Blind in U.S.A., 1940-41
}

A report on eye conditions among pupils in schools for the blind in the United States, 1940-41, was supplied by Miss C. Edith Kerby for the committee in statistics of the blind, and is published in "Outlook for the Blind, and The Teacher's Forum," Vol. XXXVI, December, 1942. This report forms the eighth of a series of annual analyses of data on eye conditions among blind children of school age in the States. It covers 75 per cent. of the present enrollment in the elementary and secondary grades of the residential schools for the blind and day classes in the public schools serving 39 states and the district of Columbia. Slight changes in distribution have occurred, but not of sufficient significance to warrant the conclusion that there have been any marked changes in the characteristics of the groups studied during the year in question. There has been a notable improvement in the completeness of the records in some schools, those which have been included in the study for some years, while in new groups there is more incompleteness. Whilst " not reported" cases now constitute a very small proportion (less than 3 per cent.) of the total for items such as present age, age at onset of blindness, amount of vision remaining and nature of eye affection, the aetiological factor in blindness remains totally unknown in 10 per cent. of cases and is identified only as "pre-natal origin, cause not specified" in an additional 38 per cent. of the total cases up to the present time.

Miss Kerby makes out a good case for much more intensive study of the history of each case, and for this service the schools for the blind should accept responsibility.

"It is discouraging to note the number of eye examination records on which recommendations for treatment or operation have been noted, and yet these pupils have remained in the 'schools for the blind year after year, with no indication that the recommendations have been carried out." And there is "the problem of the continued presence in the schools of children (amounting to nearly 12 per cent. of the pupils) who apparently have too much vision for education by tactual methods." Infectious diseases are responsible in this report for 23.9 per cent. of the blindness among children. The chief are ophthalmia neonatorum 10.9 per cent., syphilis 5.0 . per cent., and meningitis 1.8 per cent. The true figure for syphilis is probably much higher. Trauma accounted for $7 \cdot 9$ per cent.; and in 4 out of 10 of the injury cases blindness was due to sympathetic 
ophthalmitis. At least 13.5 per cent. of the blindness, in children of school age is due to heredity.

"The public should be educated regarding the potential danger to the eyes in cases of systemic disease involving either degenerative changes or nutrititional deficiencies, as well as in infectious diseases." Miss Kerby notes that 521 children in the schools for the blind during 1940-41 are there because of ophthalmia neonatorum, and 230 children are there because of syphilis pre-natally acquired. There is a folding table of the causes of blindness among pupils in the schools and day classes for the year in question, and other tables show the names of the schools with totals of pupils in each; distribution by amount of vision remaining; age distribution; and age at onset of blindness, all of which merit careful perusal.

Miss Kerby is to be congratulated on this excellent report.

\section{LIGHT AND VISION}

[Abstrict of an Address by SIR JOHN PARSONS to the Illuminating Engineering Society on May 11, 1943.

The Illuminating Engineering Society was founded by Mr. Leon Gaster in 1909 for the purpose of promoting "good lighting," i.e. lighting " adequate and suitable" for the given performance. "It was designed to represent all aspects of the subject, and its members include gas and electric light experts, physiologists, ophthalmologists, architects, and others. The writer is an original member, past president, and fellow of the Society.]

Ar the time of its inception there was little guidance in lighting matters from ophthalmologists and physiologists; but it must be remembered that information on the physical side was also vague. Although engineers were becoming accustomed to foot-candles the few instruments for measuring illumination were primitive and cumbersome. There were as yet few records of the illumination actually provided in different classes of buildings. At that time, too, the conception of brightness in terms of candles per square inch was little understood, and there were no quick and convenient means of measuring the brightness of sources.

In those days, as Sir Francis Goodenough has said (" Illuminating Engineer," Vol. xxv, p. 276, 1922), "Technicians were somewhat apt to devote themselves to the perfecting of their tools 